\title{
TGF-ß1 869T/C Polymorphism and Ischemic Stroke: Sex Difference in Chinese
}

\author{
Hong-miao Tao, Guo-zhong Chen, Xiao-dong Lu, Gan-ping Chen, Bei Shao
}

\begin{abstract}
Background: Inflammation plays a pivotal role in the pathogenesis of atherosclerosis and of cerebrovascular complications. Transforming growth factor- $\beta$ (TGF- $\beta$ ) is a pleiotropic cytokine with a central role in inflammation. To investigate whether polymorphisms of the TGF- $\beta 1$ gene can modify the risk of ischemic stroke (IS) in Chinese population, we conduct this hospital-based, case-control study. Methods: Transforming growth factor- $\beta 1$ genotype was determined in 450 Chinese patients (306 male and 144 female) with IS and 450 control subjects (326 male and 124 female). Results: Subjects carrying $869 \mathrm{TT}$ were susceptible to IS (odds ratio $[\mathrm{OR}]=1.58 ; \mathrm{P}=0.003$ ). Further analysis of IS data partitioned by gender revealed the female-specific association with $869 \mathrm{~T} / \mathrm{C}(\mathrm{OR}=2.64 ; \mathrm{P}=0.001)$. Conclusions: Findings suggest that the TT genotype of $869 \mathrm{~T} / \mathrm{C}$ might be a risk factor of IS in Chinese, especially in females.
\end{abstract}

RÉSUMÉ: Le polymorphisme TGF- $\$ 1$ 869T/C et l'accident vasculaire cérébral ischémique : différence selon le sexe chez les Chinois. Contexte : L'inflammation joue un rôle clé dans la pathogenèse de l'athérosclérose et des complications cérébrovasculaires. Le facteur de croissance transformant $\beta$ (TGF- $\beta$ ) est une cytokine pléiotrope qui joue un rôle central dans l'inflammation. Nous avons effectué cette étude cas témoins en milieu hospitalier afin de déterminer si les polymorphismes du gène TGF- $\beta 1$ pouvaient influencer le risque d'accident vasculaire cérébral ischémique (AVCI) dans la population chinoise. Méthodologie : Le génotype TGF- $\beta 1$ a été déterminé chez 450 patients Chinois (306 hommes et 144 femmes) atteints d'AVCI et chez 450 témoins (326 hommes et 124 femmes). Résultats : Les sujets porteurs de 869TT étaient plus à risque d'AVCI (RC 1,58; p =0,003). L'analyse des données selon le sexe a montré une association avec 869T/C chez les femmes (RC 2,64; p = 0,001). Conclusions : Selon ces résultats, le génotype TT de 869T/C pourrait être un facteur de risque de l'AVCI chez les Chinois, surtout chez les femmes.

Stroke is a major public health problem worldwide because it is the second most common cause of mortality and the leading cause of adult long-term disability and represents an enormous socioeconomic burden for society. ${ }^{1}$ Ischemic stroke (IS) is a complex multifactorial and polygenic disorder that is thought to result from an interaction between the individual's genetic background and various environmental factors. ${ }^{2}$ Recent advances have revealed that inflammation is an essential process in the pathogenesis of IS. ${ }^{3}$ Inflammation is influenced by many different cytokines, such as transforming growth factor- $\beta$ (TGF$\beta$ ), the most common variant of three isoforms (TGF- $\beta 1,-2$ and -3). Transforming growth factor- $\beta$ has many different functions, both pro-atherogenic and antiatherogenic. Some consider the over-all effect of TGF- $\beta$ to be protective, by reducing the risk of cerebrovascular disease. ${ }^{4-8}$ Others describe TGF- $\beta$ as inducing or facilitating cerebrovascular pathological states, such as vascular stenosis and thrombogenesis. 9-10 $^{-10}$

The TGF- $\beta 1$ gene is located on chromosome 19q13. It comprises seven exons and nine introns and produces mRNA of $2.5 \mathrm{~kb} .{ }^{11}$ There are several commonly known (potentially) functional polymorphisms in this gene. The production of TGF$\beta 1$ is predominantly under genetic control and several common single nucleotide polymorphisms (SNPs) with possible functional significance have been reported in the TGF- $\beta 1$ gene, including the -988C/A (rs1800820), -800 G/A (rs1800468), and $-509 \mathrm{C} / \mathrm{T}$ polymorphisms (rs1800469) (all in the promoter region); and 869T/C (Leu10Pro in codon10, rs1800470) and 915G/C (Arg25Pro in codon25, rs1800471) (signal peptide sequence) and 788C/T (Thr263 Ile in Exon5, rs1800474) (in the

From the School of Medicine (HMT, GZC), Jinhua College of Profession \& Technology; Department of Clinical Laboratory (XDL), Jinhua Central Hospital; Department of Neurology (GPC), Jinhua Peoples Hospital, Jinhua; Cerebrovascular Unit (BS), Department of Neurology, the First Affiliated Hospital, Wenzhou Medical College, Wenzhou, Zhejiang Province, the People's Republic of China. Received March 8, 2010. Final Revisions Submitted May 11, 2010 Correspondence to: Hong-miao Tao, School of Medicine, Jinhua College of Profession \& Technology, Jinhua, 321007, Zhejiang Province, the People's Republic of China. 
precursor part of the protein). ${ }^{12-14}$ Two SNPs, $-509 \mathrm{C} / \mathrm{T}$ and $869 \mathrm{~T} / \mathrm{C}$, exist in the Chinese population while others have little variability in the Chinese, which have been shown to be associated with the serum level of TGF- $\beta 1 .^{15-18}$ Only 869T/C was selected for our association study based on which $-509 \mathrm{C} / \mathrm{T}$ polymorphism has been shown to be in linkage disequilibrium with the $869 \mathrm{~T} / \mathrm{C}$ polymorphism. ${ }^{19}$ To date, few studies have been published on the association of the TGF- $\beta 1$ 869T/C polymorphism and risk of IS. ${ }^{20-21}$ The sparse results available are inconsistent. To our knowledge, there are no previous studies on the association of this polymorphism with risk of IS in Chinese population.

One potential explanation for these inconsistent findings is that previous studies have correlated the TGF- $\beta 1$ 869T/C polymorphism and IS but not separating analysis for sex. Sexspecific relationships between other SNPs and IS were also found in previous studies..$^{22-24}$ Therefore, we hypothesized that the association between the TGF- $\beta 1$ 869T/C polymorphisms and IS may be different according to gender. To explore this hypothesis, we undertook a case-control study of patients hospitalized with IS and examined with a separate analysis for sex specifically whether there may be an association between the TGF- $\beta 1869 \mathrm{~T} / \mathrm{C}$ polymorphism and IS according to gender.

\section{Materials ANd Methods}

\subsection{Study Population}

The study protocol included history taking, neurological examination, extracranial and transcranial ultrasound, neuroimaging and laboratory testing. This study was conducted on patients who were consecutively admitted to the Department of Neurology of Jinhua Central Hospital and Jinhua People's Hospital (July, 2008 to April, 2010). They were acute stroke patients diagnosed by performing computed tomography (CT) or magnetic resonance imaging (MRI) scan within seven days after onset. Excluded from the study were patients with (1) previous transient ischemic attack or stroke; (2) recent history of head trauma; (3) major cardiac, renal, hepatic, or cancerous disease; and (4) obvious signs of infection after admission.

Power and Sample Size Calculation Software 2.1 was used for sample size calculation. We assumed $\alpha=0.05$ (two-sided) with power $=80 \%$ using a $1: 1$ ratio of cases to controls while looking for an odds ratio (OR) of 1.5. We assumed the rate of TT genotype in the source population (controls) is $30 \%$. It indicated 425 cases and 425 controls would be needed. With the use of clinical, radiological, cardiac, and ultrasound test results, a total of 450 patients with IS (306 men and 144 women) were included in the study. All cases were examined by a neurologist and underwent neuroimaging (CT and/or MRI) and an echocardiography (ECG). Ninety-eight percent of patients had extracranial carotid and vertebral duplex ultrasound. Echocardiography (43\%) and MR angiography and/or transcranial Doppler ultrasound (13\%) were performed when clinically indicated. The 450 control subjects (326 men and 124 women) were invited to participate in a routine annual health check-up, had not any of symptoms, signs or history of IS. The subjects had a CT or MRI scan performed if diagnosis wasn't clear.
The evalulation of risk factors in both cases and controls included age, sex, body mass index (BMI, $\mathrm{kg} / \mathrm{m}^{2}$ ), hyperlipemia, smoking status, hypertension and diabetes mellitus. Systemic arterial hypertension was defined as a systolic blood pressure of $140 \mathrm{~mm} \mathrm{Hg}$, and/or a diastolic blood pressure of $90 \mathrm{~mm} \mathrm{Hg}$, at least on two separate occasions, or antihypertensive treatment. Hyperlipemia was defined as either an elevated fasting total cholesterol level above $220 \mathrm{mg} / \mathrm{dL}$ or fasting triglyceride level above $150 \mathrm{mg} / \mathrm{dL}$ or current treatment with lipid-lowering medication. ${ }^{25}$ Current or former smokers were defined as who had one year or more of tobacco. Diabetes mellitus was defined as the presence of an active treatment with insulin or an oral antidiabetic agent; for patients administered dietary treatment, documentation of a abnormal fasting blood glucose or glucose tolerance test based on the World Health Organization criteria ${ }^{26}$ was required for establishing this diagnosis.

All patients and control subjects were Chinese. They were all unrelated. Written informed consent was obtained from all subjects. The study protocol was approved by the Medical Ethics Committee of Jinhua.

\subsection{Genotyping of the TGF- $\beta 1$ gene}

Venous blood $(5 \mathrm{ml})$ was collected into tubes containing EDTA (disodium salt, 50mmol/L), and genomic DNA was isolated with a DNA extraction kit (Roche, Switzerland).

The polymorphism $869 \mathrm{~T} / \mathrm{C}$ located at codon 10 in the signal peptide sequence of TGF- $\beta 1$ was identified by the allele-specific polymerase chain reaction (AS-PCR) method. ${ }^{27}$ All the reagents for PCR were purchased from Roche Diagnostics (Roche, Switzerland). The primer synthesized at the SBS Genetech Co (Beijing, China). The primer sequence were $5^{\prime}$ AGCAGCGGTAGCAGCAGCA-3' (sense primer F1), 5' GCAGCGGTAGCAGCAGCG-3' (sense primer F2) and 5' GTCACCAGAGAAAGAGGAC-3' (antisense primer R). Reactions were performed in a total volume of $50 \mathrm{ml}$ containing $0.5 \mathrm{mg}$ of genomic DNA, 20pmol of each primer, $0.2 \mathrm{mmol} / \mathrm{L}$ each of dCTP, dTTP, dGTP, and dATP, $1 \mathrm{U}$ of Taq DNA polymerase, $50 \mathrm{mmol} / \mathrm{L} \mathrm{KCl}, 1.5 \mathrm{mmol} / \mathrm{L} \mathrm{MgCl}_{2}, 1.4 \%$ dimethyl sulfoxide, $0.01 \%$ gelatin, and $10 \mathrm{mmol} / \mathrm{L}$ Tris- $\mathrm{HCl}$ (pH8.3). The thermocycling procedure consisted of initial denaturation at $94^{\circ} \mathrm{C}$ for five minutes; followed by 30 cycles of denaturation at $94^{\circ} \mathrm{C}$ for one minute, annealing at $61^{\circ} \mathrm{C}$ for one minute, and extension at $72^{\circ} \mathrm{C}$ for 45 seconds; The final elongation step of $72^{\circ} \mathrm{C}$ for five minutes. The PCR products were analyzed by $1 \%$ agarose gel electrophoresis and visualized by ethidium bromide staining.

The target bands size for both $\mathrm{T}$ allele and $\mathrm{C}$ allele were $241 \mathrm{bp}$ for codon 10. The AS-PCR assay was conducted in two parallel experiments: one is "wild+common" primer experiment (WC) and the other is "mutant+common" primer experiment (MC). The results were interpreted from each experimental result. Three scenarios were to be detected, which were homozygous wild type (TT) heterozygous (TC) and homozygous variant type (CC) respectively. A band from WC but none from MC tube entail homozygous wild type (TT). On the other hand, single band on MC but none from $\mathrm{WC}$ tube implied homozygous variant type (CC). If target bands appeared on both $\mathrm{WC}$ and $\mathrm{MC}$ tubes, being heterozygous was inferred (TC). 
The DNA sequencing was performed on ten random samples. It confirmed the match between the product sequence and the established TGF- $\beta 1$ sequence.

\subsection{Statistical Analysis}

SPSS statistical software version 10.0 was used for statistical analysis. Data are presented as the mean \pm SD. Statistical significance was tested using unpaired Student's t-test or the Mann-Whitney U test as appropriate. Qualitative data were compared by the chi-square test. Allele frequencies were estimated by the gene-counting method, and chi-square test was performed to test for deviations from Hardy-Weinberg equilibrium. We also performed multivariable logistic regression analysis (backward: Wald elimination method) to adjust risk factors, with the type of subjects ( $1=\mathrm{IS}, 0=$ Controls) as a dependent variable and independent variables including age, BMI, smoking status $(0=$ nonsmoker, $1=$ smoker $)$, metabolic variables $(0=$ no history of hypertension, diabetes mellitus, or hyperlipemia; $1=$ positive history), TGF- $\beta 1$ genotype and $\mathrm{T}$ allele $(\mathrm{T}=1, \mathrm{C}=0)$. Transforming growth factor- $\beta 1$ genotype was calculated according to a dominant $(\mathrm{CC}=0, \mathrm{TC}=\mathrm{TT}=1)$ or recessive $(\mathrm{TC}=\mathrm{CC}=0, \mathrm{TT}=1)$ genetic model. The $\mathrm{OR}$ and $95 \% \mathrm{CI}$ were also calculated. Statistical significance was taken as $P<0.05$. (2 tailed)

\section{RESULTS}

The clinical characteristics of the study sample as a whole, and after stratification according to sex are shown in Table 1. Analyses of clinical characteristics showed no significant difference between IS and control groups for all the subjects, male and female in terms of age, BMI, the incidence of several conventional risk factors for IS including habitual smoking, diabetes mellitus, and hyperlipemia $(P>0.05$; Table 1$)$. We also found that the prevalence of hypertension differed significantly between IS patients and controls for all the subjects and male $(P<0.05$, Table 1$)$.

The genotype distributions among the male and female of the controls were in Hardy-Weinberg equilibrium. The $\mathrm{T}$ allele increased the risk of IS $(\mathrm{OR}=1.30 ; P=0.006)$ and subjects carrying TT genotype were more susceptible to IS $(\mathrm{OR}=1.56$; $P=0.003$ ). We further analyzed the data partitioned by gender. $\mathrm{T}$ allele and TT genotype were significantly associated with IS $(\mathrm{OR}=1.62 ; P=0.006, \mathrm{OR}=2.369 ; P=0.001$, respectively $)$ in females, but not in males $(P>0.05$; Table 2$)$.

The findings from the univariate analysis were further investigated in a multiple logistic model with adjustment for age (in years) and smoking habit, and conventional vascular risk factors. The TGF- $\beta 1$ 869TT genotype was identified independently related to IS (adjusted $\mathrm{OR}=1.58$; 95\%CI, 1.162.14; $P=0.003$ ). A separate analysis for sex was carried out. In female, TT genotype was also identified independently related to IS (adjusted OR=2.64; 95\%CI, 1.50-4.66; $P=0.001$ ). In male, no significant associations were found in TGF- $\beta 1$ 869T/C polymorphsim and IS.

\section{Discussion}

This study indicated subjects with 869TT genotype were independently associated with an increased risk of IS. Further analysis of IS data partitioned by gender revealed the femalespecific association with $869 \mathrm{~T} / \mathrm{C}$. Kim et $\mathrm{al}^{20}$ also detected such a gender-specific association between the $869 \mathrm{~T} / \mathrm{C}$ polymorphism and the risk of IS in Korean population. Unfortunately, the result of the association between the TT genotype and IS is not very convincing because they didn't adjusted for the common vascular risk factors. Another study, the largest study to date (more than 6000 individuals from the Rotterdam study), had failed to find any association between the $869 \mathrm{~T} / \mathrm{C}$ polymorphsim and IS in Caucasians in addictive model. ${ }^{21}$ They didn't evaluate the association between $869 \mathrm{~T} / \mathrm{C}$ polymorphsim and IS either in dominant or recessive model. Furthermore, further analysis of IS data partitioned by gender wasn't done in Caucasians. These inconsistencies may reflect the significance of separating sex analysis or adjustment of confounding factors for IS. Both of the above were considered in our study.

We do not know why the associations are only seen in females and not in males. In complex traits, gender-specific effects of autosomal genes can be usually explained by epistasis with sex-linked genes or by interaction with non-genetic factors that are correlated with sex. The epistasis with sex-linked genes often results from hormonal effects on gene expression and regulation. These sex differences are attributed in part to the protective effect of estrogen since sex differences in stroke

Table 1: Baseline characteristics of the study population

\begin{tabular}{|c|c|c|c|c|c|c|c|c|c|}
\hline \multirow[b]{2}{*}{ Characteristic } & \multicolumn{3}{|c|}{$\mathrm{A} 11$} & \multicolumn{3}{|c|}{ Female } & \multicolumn{3}{|c|}{ Male } \\
\hline & I S $(n=450)$ & $\operatorname{Ctrls}(n=450)$ & $P$ & I S $\quad(n=144)$ & Ctrls $(n=124)$ & $P$ & I S $\quad(n=306)$ & $\mathrm{Ctrls}(\mathrm{n}=326)$ & $P$ \\
\hline Age, year & $64.87 \pm 14.45$ & $63.85 \pm 13.80$ & 0.13 & $65.39 \pm 14.46$ & $65.56 \pm 13.45$ & 0.89 & $64.62 \pm 14.45$ & $63.20 \pm 13.89$ & 0.07 \\
\hline BMI, $\mathrm{kg} / \mathrm{m}^{2}$ & $24.23 \pm 7.66$ & $23.68 \pm 6.80$ & 0.11 & $24.00 \pm 4.26$ & $23.45 \pm 4.03$ & 0.13 & $24.33 \pm 8.81$ & $23.77 \pm 7.59$ & 0.22 \\
\hline Hyperlipemia, n(\%) & $93(21.98)$ & $96(22.75)$ & 0.79 & $33(24.44)$ & $28(24.14)$ & 0.96 & $60(23.61)$ & $68(22.22)$ & 0.68 \\
\hline Smoking, $n(\%)$ & $188(42.53)$ & $179(40.32)$ & 0.50 & $5(3.62)$ & $4(3.28)$ & 0.88 & $183(60.20)$ & $175(54.35)$ & 0.14 \\
\hline Hypertension, n(\%) & $268(59.56)$ & $219(48.67)$ & 0.00 & $94(65.27)$ & $69(55.65)$ & 0.11 & $174(56.86)$ & $150(46.01)$ & 0.01 \\
\hline Diabetes, n(\%) & $86(19.11)$ & $75(16.67)$ & 0.34 & $43(29.86)$ & $30(24.19)$ & 0.30 & $43(14.05)$ & $45(13.80)$ & 0.93 \\
\hline
\end{tabular}


Table 2: Distribution of TGFß1 869T/C genotype in IS and controls

\begin{tabular}{|c|c|c|c|c|c|c|c|}
\hline & & \multicolumn{2}{|l|}{ A11 } & \multicolumn{2}{|c|}{ Female } & \multicolumn{2}{|c|}{ Male } \\
\hline & & I S $(n=450)$ & Ctrls $(n=450)$ & I $S(n=144)$ & $\operatorname{Ctrls}(n=124)$ & I S $(n=306)$ & $\operatorname{Ctrls}(n=326)$ \\
\hline \multirow[t]{3}{*}{ Genotype } & $\mathrm{CC}, \mathrm{n}(\%)$ & $105(23.33)$ & $122(27.11)$ & $28(19.44)$ & $30(24.19)$ & $77(25.16)$ & $92(28.22)$ \\
\hline & $\mathrm{TC}, \mathrm{n}(\%)$ & $193(42.89)$ & $217(48.22)$ & $54(37.5)$ & $64(51.61)$ & $139(45.42)$ & $153(46.93)$ \\
\hline & TT, n $(\%)$ & $152(33.78)$ & $111(24.67)$ & $62(43.06)$ & $30(24.19)$ & $90(29.41)$ & $81(24.85)$ \\
\hline \multirow[t]{2}{*}{ Allele } & $C,(\%)$ & 44. 78 & 51.22 & 39. 19 & 50.00 & 47.88 & 51.69 \\
\hline & $\mathrm{T},(\%)$ & 55.22 & 48.78 & 61.81 & 50.00 & 52.12 & 48.31 \\
\hline \multirow[t]{2}{*}{$\mathrm{TT}+\mathrm{TC} \quad \mathrm{VS} \quad \mathrm{CC}$} & $\mathrm{P}$ & \multicolumn{2}{|c|}{0.192} & \multicolumn{2}{|c|}{0.347} & \multicolumn{2}{|c|}{0.386} \\
\hline & OR (95\%C I) & \multicolumn{2}{|c|}{$1.22(0.90-1.65)$} & \multicolumn{2}{|c|}{$1.32(0.74-2.37)$} & \multicolumn{2}{|c|}{$1.17(0.82-1.67)$} \\
\hline \multirow[t]{2}{*}{ TT VS $\mathrm{TC}+\mathrm{CC}$} & $\mathrm{P}$ & \multicolumn{2}{|c|}{0.003} & \multicolumn{2}{|c|}{0.001} & \multicolumn{2}{|c|}{0.197} \\
\hline & oR $(95 \% \mathrm{CI})$ & \multicolumn{2}{|c|}{$1.56(1.17-2.08)$} & \multicolumn{2}{|c|}{$2.37(1.40-4.01)$} & \multicolumn{2}{|c|}{$1.26(0.88-1.80)$} \\
\hline T VS C & $\begin{array}{c}\mathrm{P} \\
\mathrm{OR}(95 \% \mathrm{CI})\end{array}$ & \multicolumn{2}{|c|}{$\begin{array}{c}0.006 \\
1.30(1.08-1.56)\end{array}$} & \multicolumn{2}{|c|}{$\begin{array}{c}0.006 \\
1.62(1.15-2.28)\end{array}$} & \multicolumn{2}{|c|}{$\begin{array}{c}0.176 \\
1.17(0.93-1.45)\end{array}$} \\
\hline
\end{tabular}

sensitivity can also be abolished in females by oophorectomy. ${ }^{28,29}$ Postmenopausal estrogen use has been associated with decreased risks for stroke prevention. ${ }^{30,31}$ The study of Matsuda et $\mathrm{al}^{32}$ demonstrated that estrogen receptor-mediated trans-criptional activation was enhanced by TGF- $\beta$ signaling. It remains unknown whether the low levels of TGF- $\beta 1$ in females lead to the corresponding decline in the protective function of estrogen on stroke prevalence. Further studies are required to elucidate the detailed mechanisms underlying this gender-specific association.

Because the results of association studies can be influenced by selection bias, it is important that the study population be genetically and ethnically homogenous and that the control group be appropriate. Our study population resided in Jinhua and adjacent cities in the central part of Zhejiang province where individuals are thought to share the same ethnic ancestry and to possess a homogeneous genetic background. The distribution of TGF- $\beta 1$ genotypes in our control group was also found in HardyWeinberg equilibrium, which strongly suggests that our study population was genetically homogeneous. Furthermore, the control individuals who had no symptom, signs and history of IS were all examined CT or MRI scan if unclear diagnosis and didn't constitute a typical controls group of age-matched and sex-matched subjects that were recruited from the general population.

\section{Conclusions}

Our findings have provided evidence for the association of the $869 \mathrm{~T} / \mathrm{C}$ polymorphism of the TGF- $\beta 1$ gene with IS in Chinese females and indicated that TGFB1 is a susceptibility locus for IS. The potential usefulness of TGF- $\beta 1$ genotyping in the prevention of IS warrants further study in populations with different ethnic and racial backgrounds.

\section{LIMITATION}

Ischemic stroke is a clinically heterogeneous disorder encompassing strokes attributable to various etiologies. However, it is not possible to investigate heterogeneous genetic effects of TGF $\beta 1$ on the subtypes because of the small number of subjects. Further exploration of the possible heterogeneous genetic effects of TGF- $\beta 1$ on the IS subtypes is needed.

\section{SOURCE OF FUNDING}

This study was supported by a grant of the Jinhua Science and Technology Bureau project, Zhejiang Province, the People's Republic of China (No: 2008-3-055).

\section{REFERENCES}

1. World Health Organization. The World Health Report: shaping the future. Geneva, Switzerland: WHO; 2003.

2. Hassan A, Markus HS. Genetics and ischaemic stroke. Brain. 2000; 123(Pt 9):1784-812.

3. Libby P. Inflammation in atherosclerosis. Nature. 2002; 420(6917): 868-74.

4. Kim JS, Yoon SS, Kim YH, Ryu JS. Serial measurement of interleukin-6, transforming growth factor-beta, and S-100 protein in patients with acute stroke. Stroke. 1996;27(9):1553-7.

5. Li D, Liu Y, Chen J, et al. Suppression of atherogenesis by delivery of TGFbeta1ACT using adeno-associated virus type 2 in LDLR knockout mice. Biochem Biophys Res Commun. 2006; 344(3): 701-7.

6. Grainger DJ. Transforming growth factor beta and atherosclerosis: so far, so good for the protective cytokine hypothesis. Arterioscler Thromb Vasc Biol. 2004; 24(3):399-404.

7. Robertson AK, Rudling M, Zhou X, Gorelik L, Flavell RA, Hansson GK. Disruption of TGF- $\beta$ signaling in $\mathrm{T}$ cells accelerates atherosclerosis. J Clin Invest. 2003; 112(9):1342-50.

8. Tashiro H, Shimokawa H, Sadamatu K, Yamamoto K. Prognostic significance of plasma concentrations of transforming growth factor- $\beta$ in patients with coronary artery disease. Coron Artery Dis. 2002; 13(3):139-43.

9. Bobik A. Transforming growth factor-betas and vascular disorders. Arterioscler Thromb Vasc Biol. 2006; 26(8):1712-20.

10. Singh NN, Ramji DP. The role of transforming growth factor-beta in atherosclerosis. Cytokine Growth Factor Rev. 2006; 17(6): 487-99.

11. Fujii D, Brissenden JE, Derynck R, Francke U. Transforming growth factor beta gene maps to human chromosome 19 long arm and to mouse chromosome 7. Somat Cell Mol Genet. 1986; 12(3):281-8. 
12. Awad MR, El-Gamel A, Hasleton P, Turner DM, Sinnott PJ, Hutchinson IV. Genotypic variation in the transforming growth factor-beta1 gene: association with transforming growth factorbeta1 production, fibrotic lung disease, and graft fibrosis after lung transplantation. Transplantation.1998; 66(8):1014-20.

13. Shah R, Rahaman B, Hurley CK, Posch PE. Allelic diversity in the TGFB1 regulatory region: characterization of novel functional single nucleotide polymorphisms. Hum Genet. 2006; 119(1-2): 61-74.

14. Lu LY, Cheng HH, Sung PK, Yeh JJ, Shiue YL, Chen A. Singlenucleotide polymorphisms of transforming growth factor-beta1 gene in Taiwanese patients with systemic lupus erythematosus. J Microbiol Immunol Infect. 2004; 37(3):145-52.

15. Yang ZX, Wang $\mathrm{H}$, Gao $\mathrm{CF}, \mathrm{Xu}$ LL, Zhao WJ. Effect of polymorphisms of transforming growth factor B1 gene on HBVinduced liver cirrhosis. Natl Med J China. 2005; 85(15):1021-6.

16. Grainger DJ, Heathcote K, Chiano M, et al. Genetic control of the circulating concentration of transforming growth factor type beta1. Hum Mol Genet. 1999; 8(1):93-7.

17. Dunning AM, Ellis PD, McBride S, et al. A transforming growth factorbeta1 signal peptide variant increases secretion in vitro and is associated with increased incidence of invasive breast cancer. Cancer Res. 2003; 63(10):2610-5.

18. Yokota M, Ichihara S, Lin TL, Nakashima N, Yamada Y. Association of a T29-->C polymorphism of the transforming growth factor-beta1 gene with genetic susceptibility to myocardial infarction in Japanese. Circulation. 2000; 101(24): 2783-7.

19. The International HapMap Consortium. The International HapMap Project. Nature. 2003; 426:789-96.

20. Kim Y, Lee $\mathrm{C}$. The gene encoding transforming growth factor beta 1 confers risk of ischemic stroke and vascular dementia. Stroke. 2006; 37(11):2843-5.

21. Sie MP, Uitterlinden AG, Bos MJ, et al. TGF-beta 1 polymorphisms and risk of myocardial infarction and stroke: the Rotterdam Study. Stroke. 2006; 37(11):2667-71.

22. Carter AM, Catto AJ, Bamford JM, Grant PJ. Gender-specific associations of the fibrinogen B beta 448 polymorphism, fibrinogen levels, and acute cerebrovascular disease. Arterioscler Thromb Vasc Biol. 1997; 17(3):589-94.
23. Schurks M, Zee RY, Buring JE, Kurth T. Interrelationships among the MTHFR $677 \mathrm{C}>\mathrm{T}$ polymorphism, migraine, and cardiovascular disease. Neurology. 2008; 71(7):505-13.

24. Morrison AC, Ballantyne CM, Bray M, Chambless LE, Sharrett AR, Boerwinkle E. LPL polymorphism predicts stroke risk in men. Genet Epidemiol. 2002; 22(3):233-42.

25. Investigation committee of guideline for diagnosis and treatment of hyperlipemias, Japan Atherosclerosis Society. Guideline for diagnosis and treatment of hyperlipemias in adults. J Jpn Atheroscler Soc. 1997; 25:1-34.

26. World Health Organization Study Group Diabetes mellitus. WHO Tech Rep Ser. 1985; 727:1-104.

27. Newton CR, Graham A, Heptinstall LE, et al. Analysis of any point mutation in DNA. The amplification refractory mutation system (ARMS). Nucleic Acid Res. 1989, 17:2503-16.

28. Fukuda K, Yao H, Ibayashi S, et al. Ovariectomy exacerbates and estrogen replacement attenuates photothrombotic focal ischemic brain injury in rats. Stroke. 2000; 31(1):155-60.

29. Santizo RA, Xu HL, Ye S, Baughman VL, Pelligrino DA. Loss of benefit from estrogen replacement therapy in diabetic ovariectomized female rats subjected to transient forebrain ischemia. Brain Res. 2002; 956(1):86-95

30. Falkeborn M, Persson I, Terent A, Adami HO, Lithell H, Bergstrom R. Hormone replacement therapy and the risk of stroke. Followup of a population-based cohort in Sweden. Arch Intern Med. 1993; 153(10):1201-9.

31. Finucane FF, Madans JH, Bush TL, Wolf PH, Kleinman JC. Decreased risk of stroke among postmenopausal hormone users. Results from a national cohort. Arch Intern Med. 1993; 153(1): 73-9.

32. Matsuda t, Yamamoto T, Muraguchi A, Saatcioglu F. Cross-talk between transforming growth factor-B and estrogen receptor signaling through Smad3. J Biol Chem. 2001; 276:42908-14. 